\title{
Wärmeübertragung aus ingenieurwissenschaftlicher Sicht
}

Wie eingangs erwähnt, ignoriert die ingenieurwissenschaftliche Analyse von Wärmeübertragungsprozessen die Entropie vollständig. Sie erklärt stattdessen die Abnahme des Temperaturniveaus bei realen Wärmeübertragungen zur physikali-

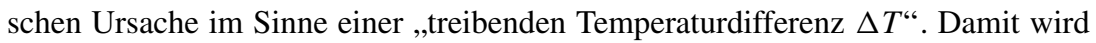
für konkrete Anwendungen ein sog. Wärmeübergangskoeffizient

$$
\alpha \equiv \frac{\dot{q}_{\mathrm{W}}}{\Delta T}
$$

eingeführt. Dieser besitzt die Einheit Watt pro Quadratmeter und Kelvin $\left(\mathrm{W} / \mathrm{m}^{2} \mathrm{~K}\right)$ und ist zahlenmäßig äußerst weit ,gefächert“. Zum Beispiel liegen typische Werte für Wärmeübertragungen bei natürlicher Konvektion zwischen 1 und 10, während bei Wärmeübertragungen mit Phasenwechsel Werte zwischen $10^{4}$ und $10^{5}$ auftreten können.

In einer etwas systematischeren Vorgehensweise wird anstelle der dimensionsbehafteten Größe $\alpha$ die dimensionslose sog. Nußelt-Zahl

$$
\mathrm{Nu}=\alpha \frac{L}{\lambda}=\frac{\dot{q}_{\mathrm{W}} L}{\lambda \Delta T}
$$

eingeführt, die eine dimensionslose Kennzahl im Sinne der Dimensionsanalyse darstellt.

Wenn nun diese Vorgehensweise mit derjenigen der Thermodynamik (Kap. 2) verglichen werden soll, bietet es sich an, den Prozess der Wärmeübertragung aus dimensionsanalytischer Sicht zu analysieren, weil dabei der physikalische Hintergrund der alternativen Betrachtungsweisen (thermodynamisch versus ingenieurwissenschaftlich) besonders deutlich wird. 